\title{
Tongue Schwannoma; A Rare Intraoral Neoplasm; Case Report
}

\author{
Dr. K. Subalakshmi ${ }^{1}$,Dr. S. Anitha Rani $\mathrm{MD}^{2}$,Dr. B. Anselm justhius fabi ${ }^{3}$, \\ Dr. R. Arun $\mathrm{MDS}^{4}$, Dr. R. Loganayagi $\mathrm{MDS}^{5}$, Dr. S. Bhagya lakshmi BDS ${ }^{6}$, \\ ${ }^{I}$ Senior Assistant Professor, Department Of Dental Surgery, Government Tiruvannamalai Medical College \\ And Hospital, Tiruvannamalai \\ ${ }^{2}$ Assistant professor ,Department Of Pathology, Government Tiruvannamalai Medical College And Hospital, \\ Tiruvannamalai. \\ ${ }^{3}$ Senior Resident, Department Of Dental Surgery, Government Tiruvannamalai Medical College And \\ Hospital, Tiruvannamalai. \\ ${ }^{4}$ Assistant Surgeon, Department Of Dental Surgery, Government Tiruvannamalai Medical College And \\ Hospital, Tiruvannamalai. \\ ${ }^{5}$ Senior Resident, Department Of Dental Surgery, Government Tiruvannamalai Medical College And \\ Hospital, Tiruvannamalai. \\ ${ }^{6}$ Consultant Dental Surgeon, Sai Skin And Dental Care Center, Tiruvannamalai.
}

Abstract: Schwannoma is one of the benign nerve sheath tumor which may arise from any myelinated nerve. It is a truely encapsulated neoplasm of the human body and always solitary. It occurs only $1-2 \%$ intraorally in which tongue is being the most common site. This article reports a case of schwannoma on the right lateral aspect of the tongue in a 27 year old female patient and its diagnosis and management.

\section{Intoduction:}

Schwannoma (Neurilemmoma) is a benign tumor of nerve sheath origin. These tumors can arise from any nerve covered with a Schwann cell sheath, which include the cranial nerves(except for the optic and olfactory), the spinal nerves and the autonomic nervous system. The tumor cells always stay on the outside of the nerve, but the tumor itself may either push the nerve aside or up against a bony structure, thereby causing damage to the affected nerve. Head and Neck schwannomas represents approximately $25-45 \%$, but only $1 \%$ have an intraoral origin. Intraoral schwannoma commonly occur in the tongue followed by the palate, floor of the mouth, buccal mucosa and mandible. ${ }^{11}$ Schwannoma of tongue the typically occurs in the $3^{\text {rd }}$ decade of life with no sex predilection.

\section{Case Report}

A 27 year old female patient visited the Dental department with the chief complaint of growth in the right side of the tongue for the past 6 months. The growth was progressive in nature and painless. There was no history of trauma or local infection. On intraoral examination $2 \times 2 \mathrm{~cm}$ growth was seen on the right lateral border of the tongue. On palpation, the growth was firm, non tender, smooth, and found to be covered with normal lingual mucosa. Tongue movements were normal. There was no cervical lymphadenopathy. Routine blood investigation was performed. All parameters were within normal limits.

Management: Under aseptic conditions, the growth was removed by complete excision under Local anesthesia and the specimen was sent for histopathological examination. The postoperative course was uneventful. The movement of the tongue was normal.

\section{Histopathological Examination:}

Histopathological report revealed a well encapsulated predominantly spindle cell having dimorphic pattern of Antoni A and Antoni B type cells suggestive of Schwannoma. Areas of palisading arrangement of nuclei suggestive of verocay bodies was also noted. 


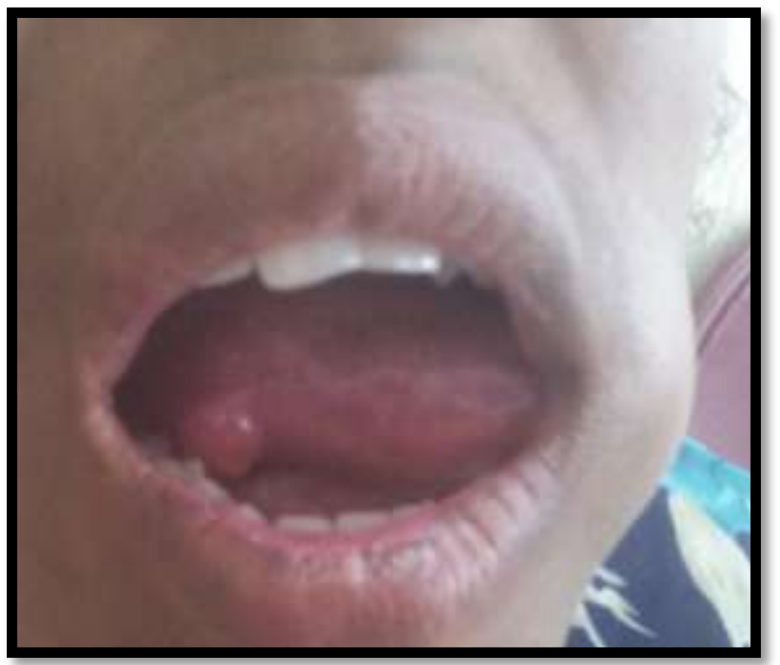

Fig 1: Intraoral photograph shows a growth present on the right lateral aspect of tongue.

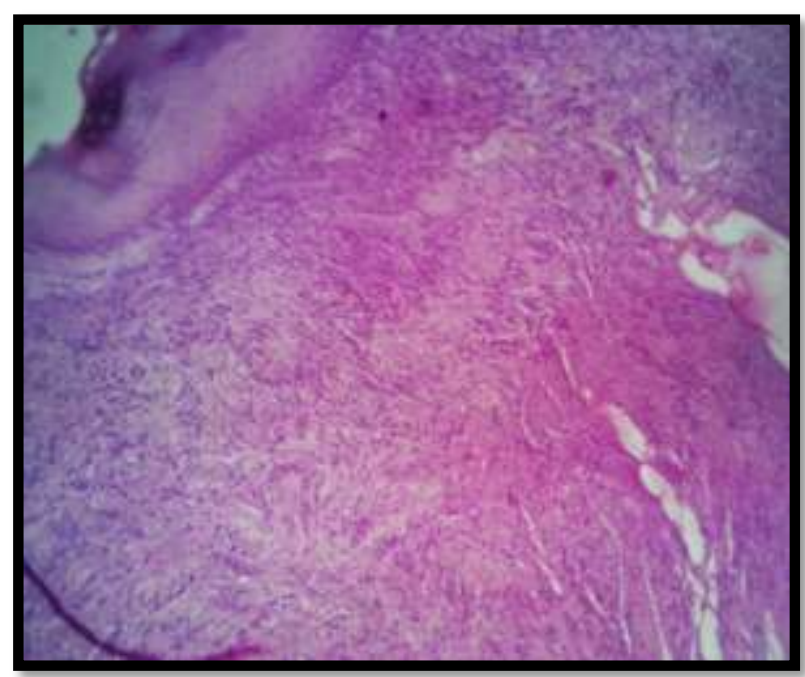

Fig 2: H\&E stained section shows Antoni A: hypercellular area and Antoni B : loosely arranged elongated Schwann cells.

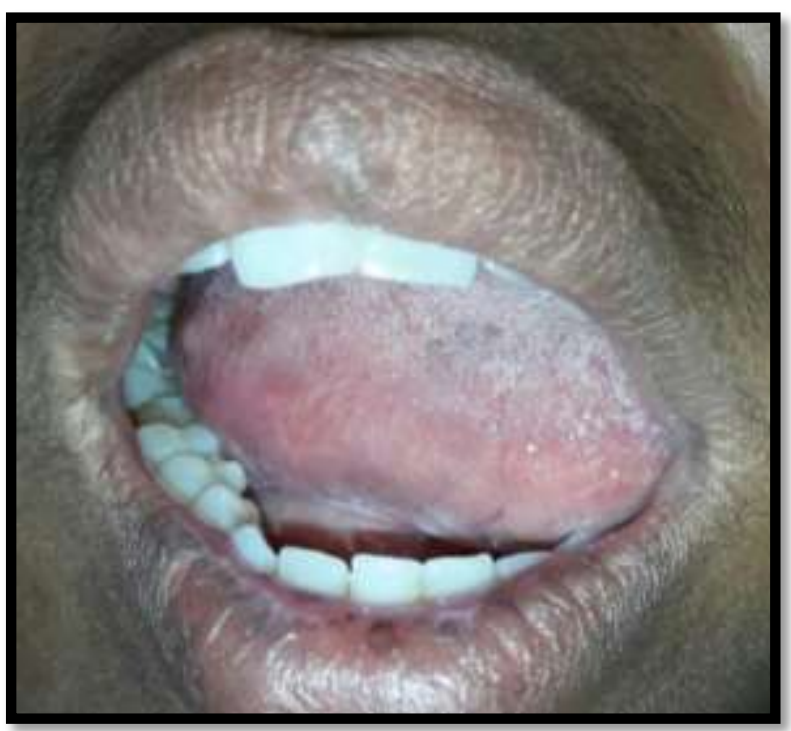

Fig 3 : Intraoral photograph showing postoperative review of the patient after 2 weeks. 


\section{Discussion}

Schwannoma is a benign encapsulated nerve sheath neoplasm composed of Schwann cells. It was first described by Verocay in $1908^{2,5}$. Embryologically, Schwann cells arise during the fourth week of development from a specialized population of ectomesenchymal cells of neural crest ${ }^{11}$. These cells forms a thin barrier around each extracranial nerve fibre of motor and sensory nerves and wrap larger fibres with myelin sheath to enhance nerve conductance.

Schwannomas commonly arise from spinal nerve roots, intracranial nerves of the face, neck, extremities, mediastinum and pelvis. The intraoral lesion show a predilection for the tongue, followed by palate, buccal mucosa, lip and gingiva ${ }^{11}$. Lopez and Ballestin in their study of nine intraoral schwannomas found three schwannomas in vestibule, two each in tongue and palate, and one each in floor of mouth and lower lip ${ }^{9}$.

They are usually solitary but multifocal lesions have also been reported. Multiple lesion occur in 1) Multiple localized neurilemmomas, 2) in association with neurofibroma in Von Recklinghausen's disease and 3) in Schwannomatosis, a non - hereditary disease characterized by multiple subcutaneous and intradermal Schwannomas along with variety of intracranial tumors. ${ }^{5,10}$ Clinically,the main differential diagnosis are other benign neoplasm, which may occur at this site. These include neurofibroma, traumatic neuroma, fibroma, lipoma, leiyomyoma etc. ${ }^{10,11}$

The histological diagnosis of Schwannoma in the presence of alternating pattern of Antoni A and Antoni B types. Antoni A is highly cellular and composed of elongated Schwann cells with disorganized palisading nuclei. Between these palisades pink areas named "verocay bodies" could be observed. Antoni B pattern consists of elongated Schwann cells with less dense myxoid morphology and more disorganized than Antoni A pattern. ${ }^{8}$ Tumors histologically simulating schwannoma are meningioma, leiyomyosarcoma, palisaded myofibroblastoma and pleomorphic hyalinizing angiectatic tumor of soft tissue. ${ }^{5}$

Malignant transformation of schwannoma in the head and neck region are unusual. Das Gupta and Brasfield found an incidence of $8 \%$ of malignant schwannomas and Ghosh et al reported an incidence of $13.9 \%$ Treatment of Schwannoma is complete surgical excision of the lesion. Different approaches for removal of tongue schwannoma have been reported. They include trans - oral, submandibular, suprahyoid pharyngotomy, and transhyoid approaches. ${ }^{4,7}$ Except for transoral approach other approaches are used for tongue base schwannoma. Recurrence is rare if complete excision is done. ${ }^{7}$

\section{Conclusion}

Schwannoma of tongue is relatively a rare tumor. Most of them have silent presentation. The final diagnosis should be done after histopathological examination and in some cases after immunohistochemical analysis. It rarely turns into malignant. A complete surgical excision is usually curative in such lesions.

\section{References}

[1]. Ballesteros F, Vilasecal, Blanch JL, Gaspa A, Bernal _ Sprekelsen M. Base of tongue neurilemmoma : excision by transoral laser microsurgery 2007.

[2]. Chiapasco M, Ronchi P, Scola G. Neurilemmoma (schwannoma) of the oral cavity; a report of 2 clinical cases. Minerva Stomatol 1993.

[3]. Das Gupta TK, Brasfield RD. Solitary Schwannoma.Ann Surg 1976.

[4]. De Bree R, Westerveld G-J, Smeele LE; Submandibular approach for excision of large Schwannoma in the base of the tongue, 2000 .

[5]. Enzinger FM, Weiss SW. Benign tumors of peripheral nerves. In: Enzinger FM, Weiss SW, editors. Soft tissue tumors, $4^{\text {th }}$ ed. Mosby: St. Louis; 1995.

[6]. Ghosh BC, Ghosh L, Huvos AG, et al. Malignant Schwannoma; A clinicopathologic study. 1973.

[7]. Hsu Y-C, Hwang C-F, Hsu R-F, Kuo F-Y, Chen C-Y Schwannoma of the tongue .2006.

[8]. Kumar V, Abbas AK, Aster JC, Robbins and Cotran, Pathologic Basis of disease, 2014.

[9]. Lopez JI, Ballestin C; Intraoral Schwannoma. A clinicopathologic study and immunohistochemical study of nine cases, Arch anat cytol pathol ,1993.

[10]. Robert OG, The Oral cavity In;Steven GS, editor. Principal and Practice of surgical pathology and cytology, Newyork: Churchill Livingstone; 1997.

[11]. Ying B, Zhu S, Qiao Y, Ye W, Maimaiti A, Hu J, Zhang Y. Surgical approaches for Tongue base Schwannoma. J craniofac surg, 2013.

[12]. Ying Y - LM, Zimmer LA, Myers EN; Base of tongue Schwannoma; a case report, 2006.

[13]. Zachariades N. Schwannoma of the oral cavity; review of the literature and report of a case, J oral Med 39:41-43, 1984. 